\title{
ROLE OF MYOFIBROBLASTS IN THE PRIMARY LESIONS AND LYMPH NODE METASTASIS OF ORAL SQUAMOUS CELL CARCINOMA
}

\author{
Hagar A. El Naggar ${ }^{1} B D s$, Manal I. El Nouaem²$P h D$, Zeinab E. Darwish ${ }^{2} P h D$, \\ Gamal A. Swaify ${ }^{3} P h D$, Marwa M. Essawy $P h D$.
}

\begin{abstract} their role in oral squamous cell carcinoma (OSCC) remains limited. histological grade, as well as to determine its correlation with metastasis in regional lymph nodes (LNs). metastasis and 15 cases without LN metastasis) and 15 normal oral mucosal tissues. correlation with the histological grades of OSCC.

CONCLUSION: $\alpha$-SMA could be used as a monitory marker in OSCC.

KEYWORDS: Oral squamous cell carcinoma, myofibroblasts, lymph node metastasis.

RUNNING TITLE: Stromal myofibroblasts in metastasizing and non-metastasizing OSCC.

1. BDS, 2014 in Oral Pathology Department, Faculty of Dentistry, AlexandriaUniversity.

2. Professor of Oral Pathology. Oral pathology Department, Faculty of Dentistry, Alexandria University.

3. Professor of Cranio-Maxillofacial and Plastic Surgery Department, Faculty of Dentistry, Alexandria University.

4. Fellow of Oral Pathology Department, Faculty ofDentistry, Alexandria University.

* Corresponding Author:

Email: hagar.elnaggar2@gmail.com
\end{abstract}

INTRODUCTION: Myofibroblasts are modified fibroblasts that express features of smooth muscle differentiation. These cells play a key role in physiologic and pathologic processes such as wound healing and tumorigenesis, respectively. Tumor cells work in close coordination with stromal elements from its stage of emergence to metastasis. Myofibroblasts are important stromal cells that play a crucial role in carcinogenesis due to its ability to modify the extracellular matrix. Alpha smooth muscle actin ( $\alpha$-SMA) is regarded as the most widely used biomarker for identifying myofibroblasts. The presence of myofibroblasts has been demonstrated in various malignant lesions. However, the number of studies evaluating

OBJECTIVES: The present study aimed to assess the presence and distribution patterns of myofibroblasts in OSCC primary tissues according to

MATERIAL AND METHODS: Immunohistochemical study using the $\alpha$-SMA antibody was done on 30 OSCC cases (15 cases with LN

RESULTS: Most of OSCC tissues showed positive immunoreactivity to $\alpha$-SMA, while normal tissues were immune-negative. The expression of $\alpha$-SMA was significantly higher in the OSCC with LN metastasis than OSCC without LN metastasis $(\mathrm{P}<0.05)$. Conversely, there was no significant

\section{INTRODUCTION}

Oral cancer is a global health problem, accounting for $2-4 \%$ of all malignancies worldwide. Oral squamous cell carcinoma (OSCC) is the most common oral malignancy, associated with high mortality rates (1). The prognosis of OSCC remains unfavourable, not-withstanding advances in diagnosis and therapy. The overall 5-year survival rate following treatment of oral squamous cell carcinoma is around $50 \%$ (2). The prognosis is heavily relying on the tumor-nodemetastasis TNM staging system, apart from many biologic, molecular, or host characteristics that are known to influence prognosis and tumor progression. Therefore, a more detailed understanding of the underlying mechanisms that lead to aggressive behavior is necessary (3).

Researches have focused on the fact that tumor progression results from an aberrant interaction between cancer cells and their activated microenvironment (4-6). Cancer milieu consists of inflammatory cells, endothelial cells, fibroblasts, extracellular matrix (ECM), proteinases, and cytokines. Of these heterogenous population, cytokines secreted from cancerous cells play a crucial role in oncogenesis. They increase the inflammatory response and provoke cancer angiogenesis. Furthermore, they promote differentiation of fibroblasts into myofibroblasts, where the stroma changes from normal to "activated" or "tumor associated (7). Myofibroblasts are large spindle-shaped cells with stress fibres and well-developed fibronexus (a cell surface specialization consisting of intracellular actin filaments and extracellular fibronectin filaments associated with subplasmalemmal plaque material). They exhibit an intermediate phenotype between fibroblasts and smooth muscle cells (8). Myofibroblasts were first discovered using electron microscopy in experimental granulation tissue by Gabbiani et al., (9). In normal human tissues, they are derived mainly from fibroblasts and also from smooth muscle cells, pericytes, macrophages, hepatic stellate cells, epithelial cells and bone marrow. Therefore, myofibroblasts are extremely heterogeneous, exhibiting different phenotypes (10). 
Transforming growth factor beta 1 (TGF- $\beta 1$ ) cytokine plays an important role in trans-differentiation of fibroblasts into myofibroblasts, while the platelet-derived growth factor (PDGF) is mainly responsible for their maturation (10).

Myofibroblasts are multifunctional cell population. They are a basic component of the granulation tissue with an important role in wound healing and chronic inflammation (11). The coordinated contraction of myofibroblasts is believed to be responsible for wound contraction and closure (8). They produce chemokines, inflammatory cytokines and prostaglandins that play important role in inflammatory response. Moreover, myofibroblasts secrete adhesion molecules like intercellular cell adhesion molecule and vascular cell adhesion molecule that help lymphocytes, mast cells, and neutrophils to associate with myofibroblasts and promote immunologic and inflammatory reactions (12). Additionally, they help in ECM reorganization by the production of numerous growth factors, and proteins of the ECM, like collagen and fibronectin (11).

In carcinogenesis, trans-differentiation of fibroblasts to myofibroblasts is considered an important event that occurs in the stroma of many invasive carcinomas (13-15). Many authors used to refer cancer associated fibroblasts (CAFs) as myofibroblasts $(8,10,15)$. Nowadays, CAFs are considered a family and myofibroblast is a family member $(6,16)$. Myofibroblasts are the most prominent stromal cell types in the tumor microenvironment (7). The tumor-promoting effect of myofibroblast is based on their capability to produce cytokines including keratinocyte growth factor, hepatocyte growth factor and fibroblast growth factor, which directly or indirectly stimulate tumor growth and invasive properties (17). Furthermore, they induce neo-angiogenesis via secretion of pre-angiogenic factors such as vascular endothelial growth factors (18). In addition, myofibroblasts secrete several enzymes such as matrix metalloproteinases (MMPs- 1, 2, 3, 9, 13, and 14), which cause ECM degradation. Therefore, they promote tumor growth, invasion, angiogenesis, and metastasis (19).

Alpha-smooth muscle actin ( $\alpha$-SMA) is regarded as the most widely used biomarker for identifying myo-fibroblastic CAFs (13). However, it cannot differentiate them from smooth muscle cells (20). Kashima et al., (21) and Cho et al., (22) reported that CAFs -detected by $\alpha$-SMA antibody- increase the probability of LN metastasis in oesophageal carcinoma and papillary thyroid carcinoma, respectively.

Even though the cells of tumour microenvironment have been illustrated in many cancers, the role of myofibroblasts is not yet fully understood especially in oral cancer. Therefore, the aim of the present work was to assess the presence and distribution patterns of myofibroblasts in OSCC according to histological grade, as well as to determine its correlation with regional lymph node metastasis.

\section{MATERIAL AND METHODS}

Sample

The current study was carried out in the Faculty of Dentistry, Alexandria University after gaining the approval of the Research Ethics Committee. It included 30 histologically confirmed cases of OSCC; 15 cases with lymph node metastasis and 15 cases without metastasis. Most of the cases were collected from the archive of the Oral Pathology Department between the period of 2015 to 2018 with few fresh tissue specimens collected from the CranioMaxillofacial and Plastic Surgery Department. Fifteen surgically excised normal mucosal tissues during minor surgeries were selected from the Oral and Maxillofacial Surgery Department serving as negative control. Informed consents were taken from the patients to participate in the study. Histological and immunohistochemical examination

The specimens were fixed in $10 \%$ neutral buffered formalin, processed and embedded in paraffin wax using the conventional procedures. Serial sections of 3-4 $\mu$ m thickness were placed on glass slides and stained using Hematoxylin and Eosin (H\&E). Histopathological diagnosis and grading of the cases were confirmed (23).

Immunohistochemical staining using $\alpha$-SMA mouse monoclonal antibody (Bio SB, USA) was performed for both primary carcinoma specimens and resected LN to assess the presence of myofibroblasts and their distribution patterns. The conventional Labeled Strept- Avidin Biotin complex method (LSAB) was used. Immunostaining was performed on $4 \mu \mathrm{m}$ paraffin sections. Sections were de-paraffinized with xylene and rehydrated in graded ethyl alcohol. Before the staining procedure, samples were immersed in citrate buffer solution $(\mathrm{pH}=6)$. Endogenous peroxidase activity was blocked with $3 \%$ hydrogen peroxide for 3 minutes. Heat induced epitope retrieval was done by boiling the sections in citrate buffer solution for 10 minutes. Then the sections were cooled for 20 minutes. Sections were incubated with primary antibody (diluted 1:100; catalog no. MS-113-P0) for 1 hour at room temperature and then were washed in phosphate-buffered saline (PBS). Finally, secondary antibody associated with Ultra Vision detection System was applied for 30 minutes at room temperature. Sections were washed in PBS again. The 3, 3 diaminobenzidine was applied as a chromogen for antibody detection. Sections were counterstained with Mayer's hematoxylin and covered with glass slip (24). Morphometric analysis

The expression of $\alpha$-SMA was evaluated in terms of percentage of immune-positive stromal cells and immunestaining intensity according to the method proposed by Tuxhorn et al., (13). The percentage of immune-positive cells among the non-inflammatory and non-endothelial stromal cells present in the connective tissue of OSCC was recorded for both study groups. In each immunohistochemically stained section, five fields were randomly selected in $\times 10$ objective lens, then cell counting was performed in $\times 40$ objective lens using counting grid containing one hundred squares. The mean number of $\alpha$-SMA positive cells per section was calculated. The percentage of immune-positive stromal cells was scored according to Kellerman's criteria (25) as follows:

$0=$ no positive cells, $1=1-33 \%$ positive cells, $2=34-66 \%$ positive cells, and $3=67-100 \%$ positive cells. Staining intensity was recorded as follows:

0 = when there was no staining;

1 = in parts, where positivity was observed only at a magnification of $\times 40$;

$2=$ in cases, where the staining was obvious at $\times 10$, but not at $\times 4$; $3=$ in fields, where immuno-positive cells were seen even at $\times 4$. Multiplication of the percentage and intensity scores comprised the staining index of each specimen. This index 
was classified as: zero $=0$, low $=1,2$, moderate $=3$, 4, and high = 6-9 (13).

Considering the distribution pattern of myofibroblasts, the positive-stained cells was classified into three groups according to Vered et al (26); 1) Focal: MFs with no special arrangement in different areas of tumor stroma, 2) Network: Interwoven network arrangement of myofibroblasts in the tumor stroma, and 3) Spindle: arrangement of MFs in one to three rows in the periphery of the neoplastic islands. The sections were blindly examined by two authors and analysis of the results was performed using computer image analyser: Image $\mathrm{J}$ free software package (NIH, USA).

\section{Statistical analysis}

The difference in the mean $\alpha$-SMA staining index between both study groups of OSCC (metastasizing and nonmetastasizing) and control group was estimated using the Ftest (ANOVA) and Post Hoc Test (Tukey). The correlation of $\alpha$-SMA expression with the histological grading of OSCC was determined using Chi square test. A (P) value less than 0.05 was considered significant. The values were given as a mean value \pm SD (standard deviation).

\section{RESULTS}

\section{Clinical results}

The age range of the patients in this study was between 38 and 74 years. Fifteen patients (50\%) were males and 15 patients (50\%) were females. The most common site of occurrence of OSCC was the lateral side of the tongue (36.7\%), followed by the buccal mucosa (16.7\%), alveolar mucosa (13.3\%), and the gingiva (10\%). Floor of the mouth, lower lip, tip of the tongue, and palate, were equally affected (6.7\% for each). Finally, both ventral surface of the tongue and retromolar area were the least sites of OSCC occurrence (3.33\% each).

Histopathological results

The microscopical examination revealed that $30 \%$ of the cases were well differentiated type, 50\% were moderately, and 20\% were poorly. Fifteen cases (50\%) were proved histologically to be associated with positive lymph node metastasis while the other 15 cases (50\%) were lymph node free.

Immunohistochemical results

All cases of normal oral mucosa $(n=15)$ showed negative immunoreactivity to $\alpha$-SMA in the connective tissue stroma except for endothelial cells lining the blood vessels (Figure 1). The connective tissue stroma of 27 OSCC biopsies were immune positive to $\alpha$-SMA, while 3 OSCC cases showed negative immunoreactivity in their stroma. The stromal myofibroblasts showed positive immunoreactivity to $\alpha$-SMA with different intensities.

Regarding $\alpha$-SMA expression in the different histological grades of OSCC, High $\alpha$-SMA staining index was seen in 4 cases $(44.4 \%)$ of well differentiated OSCC, 6 cases (40\%) of moderately, and 2 cases (33.3\%) of poorly differentiated type (Figures 2, 3 \& 4). Moderate staining index was seen in 2 cases $(22.2 \%)$ of well differentiated OSCC, 4 (26.7\%) cases of moderately and 3 (50\%) cases of poorly differentiated OSCC. Low staining index was detected only in 2 cases of well differentiated OSCC and 4 cases of moderately differentiated type repreented as $22.2 \%$ and $26.7 \%$, respectively (Figure 5).

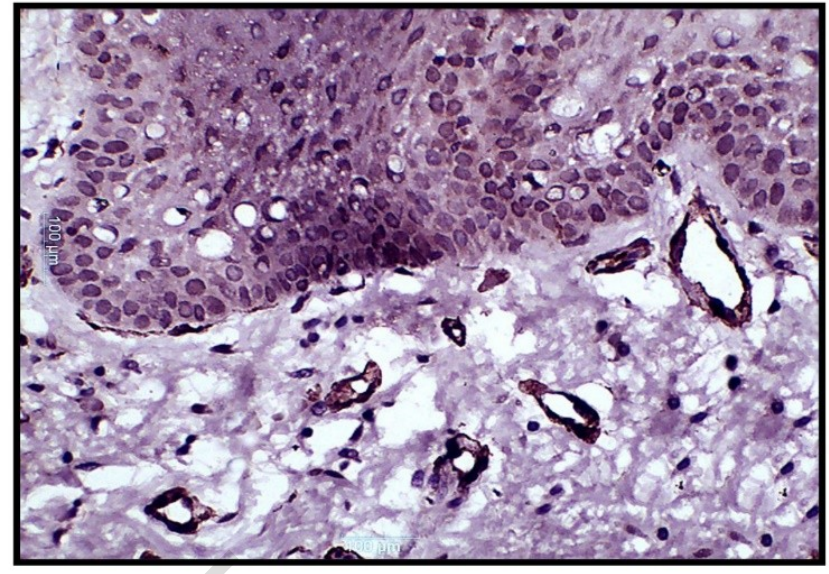

Figure (1): Higher Magnification of a Photograph Showing Positive Staining of Endothelial Cells for $\alpha$-SMA Expression $(\alpha-$ SMA x400).

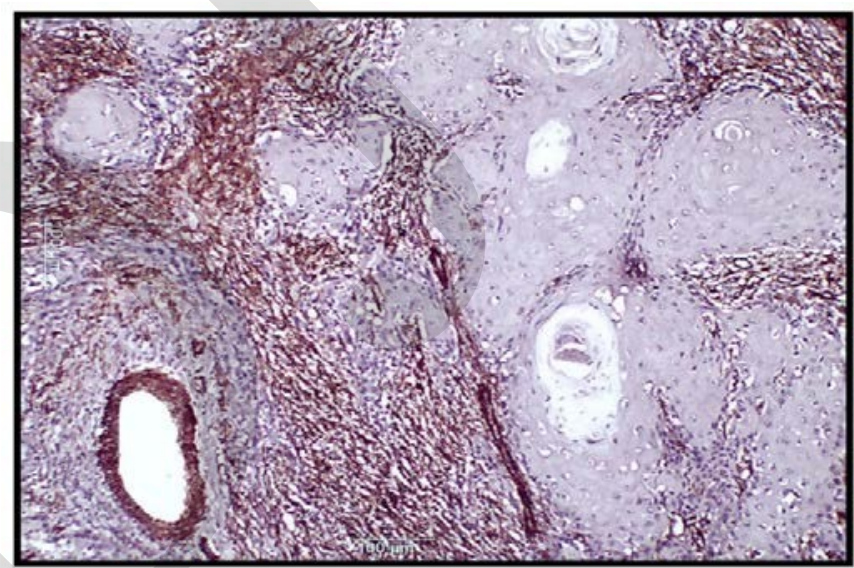

Figure (2): Intense Expression of $\alpha$-SMA in Metastasizing Well Differentiated OSCC. Notice the Network and spindle Patterns of Stromal Myofibroblasts ( $\alpha$ - SMAx100).

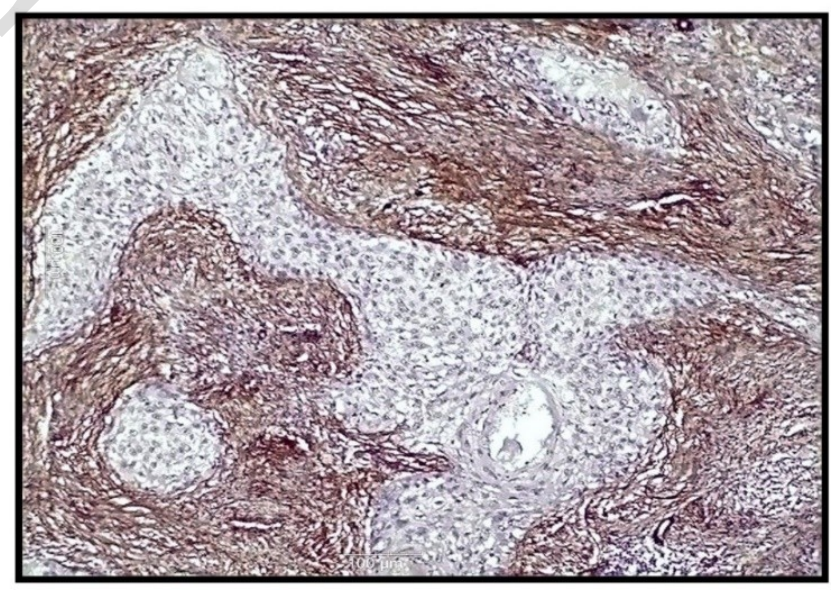

Figure (3): Intense $\alpha$-SMA Expression in Metastasizing Moderately Differentiated OSCC. Notice the Network Arrangement of Stromal Myofibroblasts ( $\alpha$-SMA x100). 


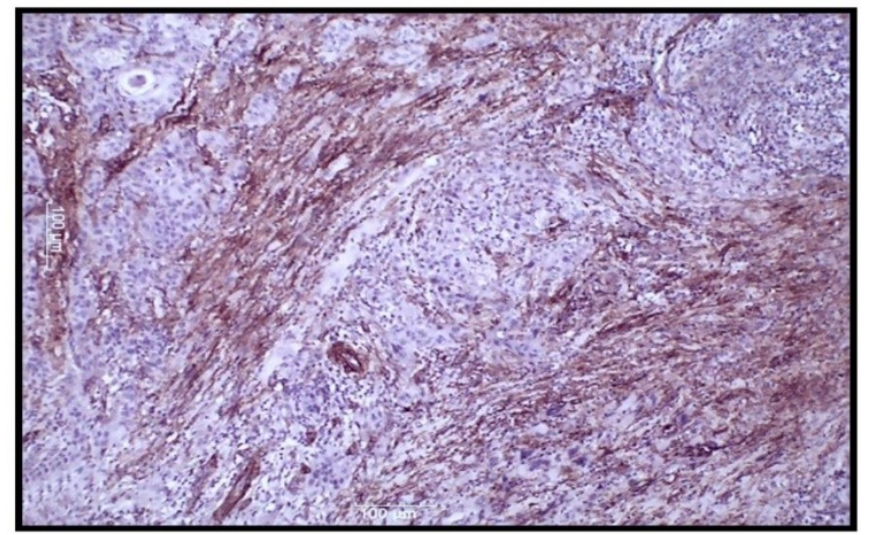

Figure (4): Intense Expression of a-SMA in Metastasizing Poorly Differentiated OSCC. Notice the Arrangement of Myofibroblasts in a Network Pattern in the Connective Tissue ( $\alpha$-SMA x100).

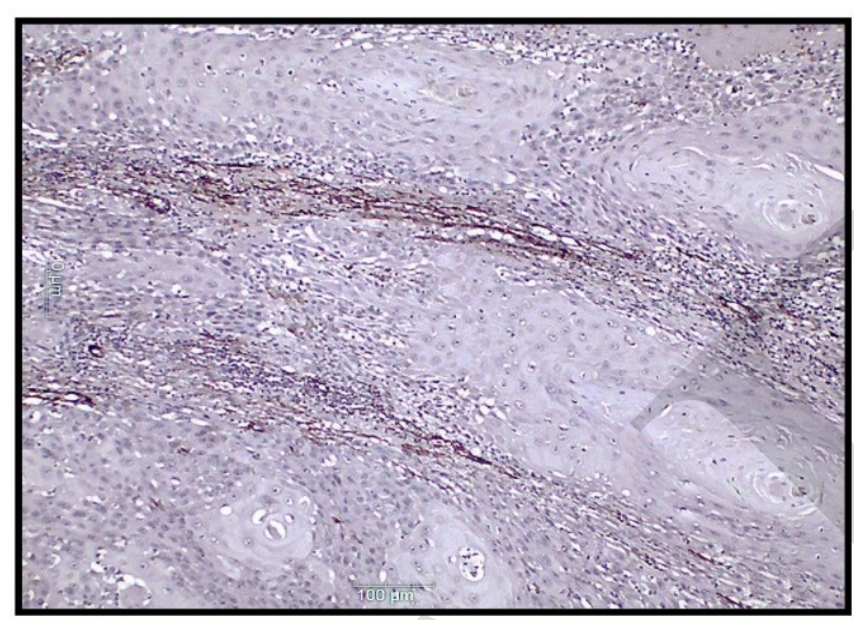

Figure (5): Weak $\alpha$-SMA Expression in Non-Metastasizing Moderately Differentiated OSCC. Notice the Focal Pattern of Stromal Myofibroblasts ( $\alpha$-SMA x100).

No statistically significant difference in the expression of $\alpha$ SMA was detected among well, moderate and poorly differentiated OSCC $(\mathrm{P}>0.05)$ (Table 1).

Table (1): Relation between histological grade of OSCC and score of $\alpha$-SMA staining index $(\mathrm{n}=30)$.

\begin{tabular}{|c|c|c|c|c|c|c|c|c|c|c|c|}
\hline \multirow{4}{*}{$\begin{array}{l}\text { Score } \\
\text { Of } \\
\alpha \text {-SMA } \\
\text { staining } \\
\text { index }\end{array}$} & \multicolumn{9}{|c|}{ Grade } & \multirow{4}{*}{$\chi^{2}$} & \multirow{4}{*}{${ }^{\mathrm{MC}} \mathrm{p}$} \\
\hline & \multicolumn{3}{|c|}{$\begin{array}{l}\text { Well } \\
(n=9)\end{array}$} & \multicolumn{3}{|c|}{$\begin{array}{l}\text { Moderate } \\
(\mathrm{n}=15)\end{array}$} & \multicolumn{3}{|c|}{$\begin{array}{l}\text { Poor } \\
(\mathrm{n}=6)\end{array}$} & & \\
\hline & \multicolumn{2}{|c|}{ No. } & \multirow[b]{2}{*}{$\%$} & No & & \multirow[b]{2}{*}{$\%$} & \multicolumn{2}{|c|}{ No. } & \multirow[b]{2}{*}{$\%$} & & \\
\hline & & $\begin{array}{l}\text { Non } \\
\text { M }\end{array}$ & & M & $\begin{array}{l}\text { Non } \\
\mathrm{M}\end{array}$ & & $\mathrm{M}$ & $\begin{array}{c}\text { Non } \\
\text { M }\end{array}$ & & & \\
\hline$\overline{\text { Zero }}$ & $\overline{0}$ & 1 & $\overline{11.1}$ & 1 & 0 & \begin{tabular}{|l|l}
6.7 \\
\end{tabular} & 0 & 1 & \begin{tabular}{|l|}
16.7 \\
\end{tabular} & & \\
\hline Low & 0 & 2 & 22.2 & 0 & 4 & 26.7 & 0 & 0 & 0.0 & & \\
\hline Moderate & 0 & 2 & 22.2 & 2 & 2 & 26.7 & 2 & 1 & 50.0 & 3.555 & 0.807 \\
\hline High & 4 & 0 & 44.4 & 4 & 2 & 40.0 & 2 & 0 & 33.3 & & \\
\hline
\end{tabular}

\section{$\chi^{2}$ : Chi square test $\quad$ MC: Monte Carlo}

M: Metastasizing OSCC (cases with lymph node metastasis)

Non-M: Non metastasizing OSCC (cases without lymph node metastasis)

$\mathrm{p}$ : $\mathrm{p}$ value for comparing between the three categories

$*$ : Statistically significant at $\mathrm{p} \leq 0.05$
Concerning $\alpha$-SMA expression in primary tumor of both study groups: The metastasizing OSCC revealed high $\alpha$-SMA staining index in 10 cases $(71.4 \%)$ and moderate staining index in 4 cases (28.6\%) (Figures 2, 3 \& 4). Low staining index wasn't detected in the metastasizing group (Table 2). In non-metastasizing OSSC, 2 cases (15.4\%) only were with high staining index, 5 cases $(38.5 \%)$ were with moderate staining index and 6 cases (46.2\%) were with low staining index (Figure 5). The presence of myofibroblasts was significantly higher in the OSCC with LN metastasis than OSCC without LN metastasis ( $<<0.05)$ (Table 2).

Table (2): Comparison between the three studied groups according to score of $\alpha$-SMA staining index.

\begin{tabular}{|c|c|c|c|c|c|c|c|c|}
\hline \multirow{3}{*}{$\begin{array}{l}\text { Score of } \alpha- \\
\text { SMA staining } \\
\text { index }\end{array}$} & \multicolumn{5}{|c|}{ Study } & \multirow{3}{*}{$\begin{array}{r}\text { Control } \\
(\mathrm{n}=15)\end{array}$} & \multirow{3}{*}{$\begin{array}{l}\text { Test } \\
\text { of sig. }\end{array}$} & \multirow{3}{*}{ P } \\
\hline & \multicolumn{2}{|c|}{\begin{tabular}{|l|}
$\begin{array}{l}\text { Group A } \\
(\mathrm{n}=15)\end{array}$ \\
\end{tabular}} & \multicolumn{2}{|c|}{$\begin{array}{l}\text { Group } \\
(\mathrm{n}=15)\end{array}$} & & & & \\
\hline & No. & $\%$ & No. & $\%$ & No. & & & \\
\hline Zero & 1 & 6.7 & 2 & 13.3 & 15 & 100.0 & \multirow{4}{*}{$\begin{array}{c}\chi^{2}= \\
44.939^{*}\end{array}$} & \multirow{4}{*}{$\begin{array}{c}{ }^{\mathrm{MC}} \mathrm{p} \\
<0.001\end{array}$} \\
\hline Low & 0 & 0.0 & 6 & 46.2 & 0 & 0.0 & & \\
\hline Moderate & 4 & 28.6 & 5 & 38.5 & 0 & 0.0 & & \\
\hline High & 10 & 71.4 & 2 & 15.4 & 0 & 0.0 & & \\
\hline Min. - Max. & \multicolumn{2}{|c|}{$0.0-9.0$} & \multicolumn{2}{|c|}{$0.0-9.0$} & & $0.0-0.0$ & \multirow{3}{*}{$\mathrm{F}=28.0^{*}$} & \multirow{3}{*}{$<0.001^{*}$} \\
\hline Mean \pm SD. & \multicolumn{2}{|c|}{$5.87 \pm 2.50$} & \multicolumn{3}{|c|}{$3.20 \pm 2.7 €$} & $0.0 \pm 0.0$ & & \\
\hline Median (IQR) & \multicolumn{2}{|c|}{$6.0(4.0-9.0)$} & \multicolumn{3}{|c|}{$2.0(1.0-4.0)$} & 0.0 & & \\
\hline Sig. bet. Grps55 & \multicolumn{6}{|c|}{$\mathrm{p}_{1}=0.004^{*}, \mathrm{p}_{2}<0.001^{*}, \mathrm{p}_{3}=0.001^{*}$} & & \\
\hline
\end{tabular}

2: Chi square test MC: Monte Carlo

F: F for ANOVA test, Pairwise comparison bet. each 2 groups was done using Post Hoc Test (Tukey)

$\mathrm{p}$ : $\mathrm{p}$ value for comparing the three groups

$\mathrm{p} 1$ : $\mathrm{p}$ value for comparing group A and group $\mathrm{B}$

$\mathrm{p} 2$ : $\mathrm{p}$ value for comparing group $\mathrm{A}$ and control

p3: p value for comparing group B and control

*: Statistically significant at $\mathrm{p} \leq 0.05$

Considering the distribution patterns of stromal myofibroblasts: They were mainly network in 11 cases (73.3\%) and spindle in 10 cases (66.7\%) of OSCC with LN metastasis (Figures 2, 3, 4 \& 6).

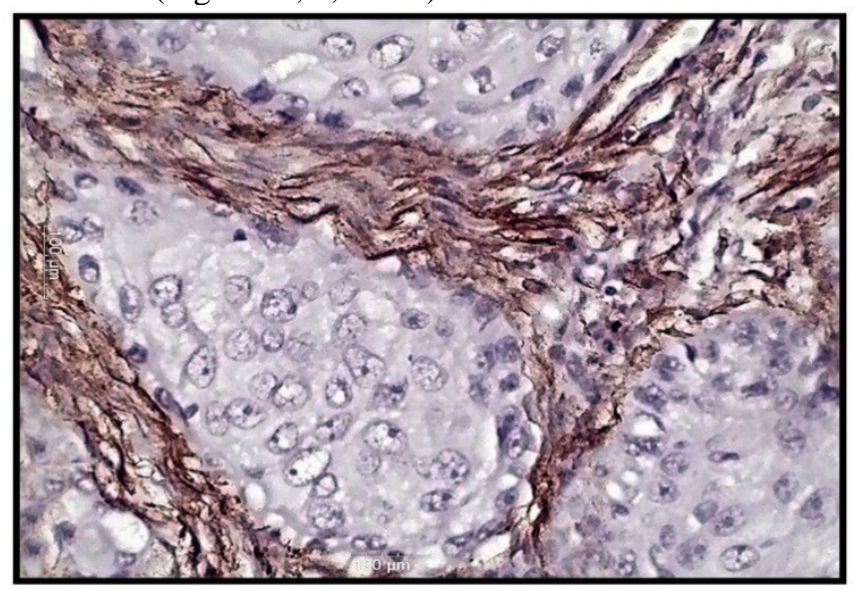

Figure (6): Spindle Pattern of Stromal Myofibroblasts in Metastasizing Moderately Differentiated OSCC ( $\alpha$-SMA x400).

Meanwhile, focal distribution was the predominant pattern observed in 9 cases (60\%) of OSCC without LN metastasis (Figure 5). No significant correlation was detected between the pattern of Myofibroblasts and the lymph node status 
$(\mathrm{P}>0.05)$ (Table 3).

Table (3): Comparison between the two studied groups of OSCC according to distribution pattern of stromal myofibroblast.

\begin{tabular}{|c|c|c|c|c|c|c|}
\hline \multirow{3}{*}{$\begin{array}{l}\text { Distribution pattern } \\
\text { of } \quad \text { stromal } \\
\text { myofibroblast }\end{array}$} & \multicolumn{4}{|c|}{ Study } & \multirow{3}{*}{$\chi^{2}$} & \multirow{3}{*}{$\mathrm{P}$} \\
\hline & \multicolumn{2}{|c|}{$\begin{array}{l}\text { Group } \\
(n=15)\end{array} \quad$ A } & \multicolumn{2}{|c|}{$\begin{array}{l}\text { Group } \\
(n=15)\end{array} \quad$ B } & & \\
\hline & No. & $\%$ & No. & $\%$ & & \\
\hline Spindle & 10 & 66.7 & 5 & 33.3 & 3.333 & 0.679 \\
\hline Network & 11 & 73.3 & 7 & 46.7 & 2.222 & 0.136 \\
\hline Focal & 3 & 20 & 9 & 60 & 3.472 & 0.624 \\
\hline
\end{tabular}

$\chi^{2}$ : Chi square test

$\mathrm{p}$ : $\mathrm{p}$ value for comparing between the two groups

*: Statistically significant at $\mathrm{p} \leq 0.05$.

\section{DISCUSSION}

The role of non-neoplastic stromal cells in tumor progression and spread has been studied in epithelial malignancies occurring in various anatomical locations $(14,27,28)$. Myofibroblast is one of the non neoplastic cells which has been implicated in tumor growth and spread (21).

In the present research, no myofibroblasts were detected in normal oral mucosal tissues. This was parallel to the data reported by Pinisetti et al., (10), Rao S et al., (29) and Gupta et al., (30). Additionally, the presence of myofibroblasts was significantly higher in OSCCs compared to the normal mucosa, suggesting that stromal myofibroblasts in OSCC may have an important role in the invasion of malignant epithelial cells (9). This finding was in accordance with those reported by Joshi et al., (7), Jayaraj et al., (31), and Smitha et al., (20). The present work showed heterogenous distribution of myofibroblasts in the tumor stroma, where they were abundant in one area and nearly absent in others within the same sample. This heterogeneity in the presence of myofibroblasts has been previously mentioned by Rao et al., (29) and Smitha et al., (20). Accordingly, this may be the reason behind $\alpha$-SMA was negatively expressed in one poorly differentiated case in the present study where there was very little stroma available for evaluation. The hetrogenous distribution of myofibroblasts in the tumor stroma may be attributed to varied secretion of TGF- $\beta$ by the tumor cells which promote trans-differentiation of fibroblasts into myofibroblasts as suggested by Jayaraj et al (31).

In the current study, the distribution of myofibroblasts was confined to the stroma immediately adjacent to the tumor islands whereas malignant cell free stroma was lacking myofibroblasts. Kellermann et al., (32) reported similar findings, thus stressing a close contact between epithelial and stromal cells is required for the induction of $\mathrm{MF}$ differentiation. This close proximity of tumor cells and myofibroblasts also supports the hypothesis that myofibroblasts can possibly be derived from the epithelial mesenchymal transition of the tumor cells. This hypothesis was proved in cases of human tongue carcinomas (26).

Additionally, inverse distribution relationship was observed with inflammatory cell infiltration in the present study. It was noticed that tumor stroma that was heavily infiltrated with inflammatory cells showed negative expression for $\alpha$-SMA. This was seen in the moderately and well differentiated OSCC cases. This was in agreement with the study conducted by Rao S et al., (29); who stated that thick band of myofibroblasts in between tumor islands and inflammatory cells gave an impression of myofibroblasts being a barrier. These findings may point to the fact that the presence of stromal myofibroblasts may be dependent on the inflammatory cell infiltration and amount of tumor stroma available for evaluation.

Statistical correlation was found to be non-significant among the 3 histological grades; well, moderately and poorly differentiated OSCC regarding $\alpha$-SMA expression. The results of the current study were consistent with the results reported by Kellermann et al., (32), Etemad et al., (33) and Ghandi et al., (34) who did not find positive correlation between OSCC histological grade of differentiation and the presence of myofibroblasts.

The present research also revealed that high $\alpha$-SMA staining index was seen in $44.4 \%$ of well differentiated OSCC and in $33.3 \%$ of poorly differentiated OSCC cases (Table 1). This was also found in other studies which mentioned that myofibroblasts formed thicker syncytium around tumor islands in well-differentiated tumors while in poorly differentiated ones, they were loosely arranged throughout stroma. In contrary to the present observations, Gupta et al.,

(30) and Bhattacharjee et al., (35) found that the expression of $\alpha$-SMA was higher in the poorly differentiated OSCC than in other grades with non-significant statistical difference. This discrepancy could be due to different methodology used for the evaluation of myofibroblasts as myofibroblasts' count in their studies was only used for evaluation whereas in the present study the staining intensity was also used. These findings suggested that the formation and differentiation of myofibroblasts are induced somehow in the invasive stage of OSCC irrespective of tumor cell differentiation (33).

In the present study, expression of $\alpha$-SMA staining index was significantly higher in OSCC with LN metastasis when compared to OSCC without LN involvement. Similar results were found by Smitha et al., (20), Kellermann et al., (32) and Sidhara et al., (36).

The current study was in agreement with that of Seifi et al., (37) and Rao S J et al., (29) and Vered et al., (26) regarding the distribution patterns where focal pattern predominated in OSCC without LN involvement, while network pattern predominated in OSCC with LN metastasis. However, no significant association was observed between the patterns of MF distribution and the LN status.

In the current study, $\alpha$-SMA was found to be expressed in areas surrounding the tumor islands in all lymph nodes with metastasis. This immune-expression pattern of $\alpha$-SMA was described in lymph nodes associated with other carcinomas such as colorectal carcinoma (38) and intra hepatic cholagenocarcinoma (39). It was proved that myofibroblasts are substantially activated when metastases reach the lymph nodes. This strongly suggested that the metastatic tumorcells attempt to recreate the microenvironment found in the primary tumors (40). In LNs without metastasis, a rim of myofibroblasts was seen within the capsule surrounding the non-metastatic lymph nodes, but not within the nodes. This was in accordance with other studies on myofibroblasts' site in lymph node $(10,40)$.

\section{CONCLUSION}

The presence of myofibroblasts was significantly higher in OSCC with LN metastasis compared to OSCC without LN involvement, thus myofibroblasts may be used as a predictive marker for LN metastasis in OSCC. Further studiesincluding 
patient follow up may support the possibility of using myofibroblasts as a prognostic marker.

\section{CONFLICT OF INTEREST}

The authors declare that they have no conflicts of interest.

\section{REFERENCES}

1. Irimie AI, Ciocan C, Gulei D, Mehterov N, Atanasov AG, Dudea D, et al. Current Insights into Oral Cancer Epigenetics. Int J Mol Sci. 2018;19: pii: E670.

2. Warnakulasuriya S. Prognostic and predictive markers for oral squamous cell carcinoma: The importance of clinical, pathological and molecular markers. SJMMS.2014;2:12-6.

3. Blatt S, Kruger M, Ziebart T, Sagheb K, Schiegnitz E, Goetze E, et al. Biomarkers in diagnosis and therapy of oral squamous cell carcinoma: A review of the literature. J Cranio Maxill Surg. 2017;45:722-30.

4. Bremnes RM, Dønnem T, Al-Saad S, Al-Shibli K, Andersen S, Sirera R, et al. The role of tumor stroma in cancer progression and prognosis: emphasis on carcinoma-associated fibroblasts and non-small cell lung cancer. J Thorac Oncol. 2011;6:209-17.

5. Werb Z, Lu P. The Role of Stroma in Tumor Development. Cancer J. 2015;21:250-3.

6. Yoshida GJ, Azuma A, Miura Y, Orimo A. Activated Fibroblast Program Orchestrates Tumor Initiation and Progression; Molecular Mechanisms and the Associated Therapeutic Strategies. Int J Mol Sci. 2019;20:E2256.

7. Joshi PS, Patil J, Chougule M, Dudanakar M, Hongal BP. Evaluation of stromal myofibroblasts in epithelial dysplasia and oral squamous cell carcinoma: An immunohistochemical study. Clin Cancer Investig J. 2016;5:441-6.

8. Bagul N, Ganjre A, Goryawala S, Kathariya R, Dusane S. Dynamic role of myofibroblasts in oral lesions. World $\mathrm{J}$ Clin Oncol. 2015;6:264.

9. Gabbiani G, Ryan G, Majno G. Presence of modified fibroblasts in granulation tissue and their possible role in wound contraction. Experientia. 1971;27:549-50.

10. Pinisetti S, Manyam R, Suresh B, Aparna V. Myofibroblasts in oral lesions: A review. Journal of oral and maxillofacial pathology : JOMFP. 2014;18:52-7.

11. Darby IA, Laverdet $B$, Bonté $F$, Desmoulière $A$. Fibroblasts and myofibroblasts in wound healing. Clin Cosmet Investig Dermatol. 2014;7:301-11.

12. Schurch W ST, Hinz B, Gabbiani G. Histology for Pathologists. Philadelphia: Lippincott-Williams and Wilkins Publishers; 2007.

13. Tuxhorn JA, Ayala GE, Smith MJ, Smith VC, Dang TD, Rowley DR. Reactive stroma in human prostate cancer: induction of myofibroblast phenotype and extracellular matrix remodeling. Clin Cancer Res. 2002;8:2912-23.

14. Zhou J, Wang XH, Zhao YX, Chen C, Xu XY, Sun Q, et al. Cancer-Associated Fibroblasts Correlate with TumorAssociated Macrophages Infiltration and Lymphatic Metastasis in Triple Negative Breast Cancer Patients. J Cancer. 2018;9:4635-41.

15. Rao S, Rao J, Bm J, Vk V. Mysterious Myofibroblast: A Cell with Diverse Origin and Multiple Functions. J Interdiscip Histopathol. 2016;5:12-7.

16. LeBleu VS, Kalluri R. A peek into cancer-associated fibroblasts: origins, functions and translational impact. Dis Model Mech. 2018;11:pii:dmm029447.

17. Tao L, Huang G, Song H, Chen Y, Chen L. Cancer associated fibroblasts: An essential role in the tumor microenvironment. Oncol Lett. 2017;14:2611-20.

18. Sewell-Loftin MK, Bayer SVH, Crist E, Hughes T, Joison SM, Longmore GD, et al. Cancer-associated fibroblasts support vascular growth through mechanical force. Sci Rep. 2017;7:12574.

19. Kessenbrock K, Plaks V, Werb Z. Matrix metalloproteinases: regulators of the tumor microenvironment. Cell. 2010;141:52-67.

20. Smitha A, Rao K, Umadevi H, Smitha T, Sheethal H, Vidya M. Immunohistochemical study of alpha-smooth muscle actin expression in oral leukoplakia and oral squamous cell carcinoma. J Oral Maxillofac Pathol. 2019;23:59-64.

21. Kashima H, Noma $K$, Ohara $T$, Kato $T$, Katsura $Y$, Komoto S, et al. Cancer-associated fibroblasts (CAFs) promote the lymph node metastasis of esophageal squamous cell carcinoma. Int J Cancer. 2019;144:828-40.

22. Cho JG, Byeon HK, Oh KH, Baek SK, Kwon SY, Jung $\mathrm{KY}$, et al. Clinicopathological significance of cancerassociated fibroblasts in papillary thyroid carcinoma: a predictive marker of cervical lymph node metastasis. Eur Arch Otorhinolaryngol. 2018;275:2355-61.

23. National Society for Histotechnology (NSH). Guidelines for Hematoxylin and Eosin Staining. 2001. Available at: www.nsh.org.

24. Bratthauer GL. The avidin-biotin complex (ABC) method and other avidin-biotin binding methods. Methods Mol Biol. 2010;588:257-70.

25. Kellermann MG, Sobral LM, da Silva SD, Zecchin KG, Graner E, Lopes MA, et al. Myofibroblasts in the stroma of oral squamous cell carcinoma are associated with poor prognosis. Histopathology. 2007;51:849-53.

26. Vered M, Allon I, Buchner A, Dayan D. Stromal myofibroblasts accompany modifications in the epithelial phenotype of tongue dysplastic and malignant lesions. Cancer Microenviron. 2009;2:49-57.

27. Galdiero MR, Varricchi G, Loffredo S, Bellevicine C, Lansione T, Ferrara AL, et al. Potential involvement of neutrophils in human thyroid cancer. PloS one. 2018;13:e0199740.

28. Cadamuro M, Brivio S, Mertens J, Vismara M, Moncsek A, Milani C, et al. Platelet-derived growth factor-D enables liver myofibroblasts to promote tumor lymphangiogenesis in cholangiocarcinoma. J Hepatol. 2019;70:700-9.

29. Rao SJ, Rao JBM, Rao PJ. Immunohistochemical analysis of stromal fibrocytes and myofibroblasts to envision the invasion and lymph node metastasis in oral squamous cell carcinoma. JOMFP. 2017;21:218-23.

30. Gupta K, Metgud R, Gupta J. Evaluation of stromal myofibroblasts in oral leukoplakia, oral submucous fibrosis, and oral squamous cell carcinoma--an immunohistochemical study. J Cancer Res Ther. 2015;11:893-8.

31. Jayaraj G, Sherlin HJ, Ramani P, Premkumar P, Natesan A. Stromal myofibroblasts in oral squamous cell 
carcinoma and potentially malignant disorders. Indian J Cancer. 2015;52:87-92.

32. Kellermann MG, Sobral LM, da Silva SD, Zecchin KG, Graner E, Lopes MA, et al. Mutual paracrine effects of oral squamous cell carcinoma cells and normal oral fibroblasts: induction of fibroblast to myofibroblast transdifferentiation and modulation of tumor cell proliferation. Oral Oncol. 2008;44:509-17.

33. Etemad-Moghadam S, Khalili M, Tirgary F, Alaeddini M. Evaluation of myofibroblasts in oral epithelial dysplasia and squamous cell carcinoma. J Oral Pathol Med. 2009;38:639-43.

34. Gandhi P, Prasad UC. Evaluation of myofibroblasts in oral submucous fibrosis and oral squamous cell carcinoma: The pathogenesis and correlation. Dent Res J (Isfahan). 2017;14:314-20.

35. Bhattacharjee K, Girish HC, Murgod S, Alshame AMJ, Shyamala K, Nayak VN. A Comparative Immunohistochemical Study of Presence and Distribution Pattern of Stromal Myofibroblast in Oral Dysplasia and in Different Grades of Oral Squamous Cell Carcinoma. J Int Soc Prev Community Dent. 2018;8:451-6.
36. Sridhara SU, Choudaha N, Kasetty S, Joshi PS, Kallianpur $\mathrm{S}$, Tijare M. Stromal myofibroblasts in nonmetastatic and metastatic oral squamous cell carcinoma: An immunohistochemical study. JOMFP. 2013;17:190-4.

37. Seifi S, Shafaei S, Shafigh E, Sahabi SM, Ghasemi H. Myofibroblast stromal presence and distribution in squamous epithelial carcinomas, oral dysplasia and hyperkeratosis. APJCP. 2010;11:359-64.

38. Yeung TM, Buskens C, Wang LM, Mortensen NJ, Bodmer WF. Myofibroblast activation in colorectal cancer lymph node metastases. Br J Cancer. 2013;108:2106-15.

39. Itou RA, Uyama N, Hirota S, Kawada N, Wu S, Miyashita $\mathrm{S}$, et al. Immunohistochemical characterization of cancerassociated fibroblasts at the primary sites and in the metastatic lymph nodes of human intrahepatic cholangiocarcinoma. Hum Pathol. 2019;83:77-89.

40. Parajuli H, Teh MT, Abrahamsen S, Christoffersen I, Neppelberg E, Lybak $\mathrm{S}$, et al. Integrin $\alpha 11$ is overexpressed by tumor stroma of head and neck squamous cell carcinoma and correlates positively with alpha smooth muscle actin expression. J Oral Pathol Med. 2017;46:267-75. 